\title{
Córregos urbanos do município de Cáceres-MT, Brasil: um olhar para a conservação
}

\author{
Urban streams of the city of Cáceres-MT, Brazil: a look for conservation \\ Ernandes Sobreira Oliveira-Junior', Bárbara Ferraz Buhler², \\ Claumir Cesar Muniz ${ }^{3}$, Amabilen Oliveira Furlan ${ }^{4}$ \\ 1, 3,4 Universidade do Estado De Mato Grosso, MT - Brasil \\ ${ }^{2}$ Secretaria Estadual de Saúde de Mato Grosso, MT - Brasil
}

\begin{abstract}
Resumo
Os córregos urbanos constituem uma importante fonte de recursos naturais para as populações humanas, mas, a despeito disso, sofrem com a degradação e com o descaso do poder público e da sociedade em geral. Este trabalho teve como objetivo analisar os aspectos físicos dos córregos urbanos de Cáceres-MT, município considerado o portal de entrada do Pantanal Matogrossense. Para tanto, os córregos, previamente selecionados, foram observados quanto aos aspectos físicos (vegetação marginal, estado geral de preservação, odor, diversidade da biota local e ocupação do entorno) da nascente até a foz. Dos quatro córregos analisados, três apresentaram alto grau de degradação em todo o trecho (nascente, médio curso e foz). Apenas a foz do Córrego Fontes foi considerada natural - sem impactos. Os demais córregos, Sangradouro, José Bastos e Canal do Renato, bem como o Córrego Fontes no médio curso, continham grande quantidade de lixo e sinais de eutrofização (macrófitas em abundância no leito). Foi possível concluir que a observação visual dos aspectos físicos de um dado recurso natural pode contribuir para a análise da qualidade ambiental, bem como pode fornecer dados importantes com vistas na implementação de planos de manejo adequados para a conservação local e planejamento urbano.
\end{abstract}

Palavras-chave: Mananciais urbanos, descaso populacional, ambientes insalubres.

\begin{abstract}
The urban streams are an important source of natural resources for human populations, but despite of it, suffer from degradation and the indifference of the public and society in general. This study aimed to analyze the physical aspects of the main urban streams in Caceres-MT, municipality considered the gateway to the Pantanal. To this end, streams, previously selected, were observed regarding physical (riparian vegetation, general maintenance, odor, local biota diversity, and surroundings occupation) from the source to the mouth. The streams studied had a high degree of degradation in the whole section (headwaters, middle course and mouth). Only the Fontes mouth was considered natural, without impact. Other streams, Sangradouro, Jose Renato, and Bastos, also the Fontes stream in the middle course, contained large amounts of garbage and very evident signs of eutrophication (macrophytes in abundance). It was concluded that visual observation of the physical aspects of a given natural resource can contribute to the analysis of environment quality, and can provide important data with a view to implement appropriate management plans for the conservation site..
\end{abstract}

Key-words: Urban watersheds, neglect population, unhealthy environments. 


\section{INTRODUÇÃO}

A população urbana aumentou consideravelmente com o advento da Revolução industrial; a partir de então, as cidades passaram a sofrer com o inchaço populacional, devido, sobretudo a ausência de planejamento. O crescimento demográfico desordenado tem causado sérios prejuízos ao meio ambiente. Medidas públicas paliativas têm sido implantadas com intuito de minimizar os problemas causados pela má ocupação do solo, deposição de resíduos sólidos, lançamento de efluentes, porém, na maioria das vezes, não resolvem a situação por serem projetos que não correspondem com a engenharia adequada, provocando problemas ainda maiores para os moradores das regiões afetadas (TUCCI et al. 2003).

Vários aspectos devem ser considerados quando se fala em preservação do meio ambiente urbano, dentre eles destacam-se: uso e ocupação do solo, saneamento básico, deposição adequada de resíduos sólidos, proteção de mananciais, manejo de áreas florestadas e fiscalização/ monitoramento da qualidade ambiental (SUNDFELD, 2003).

Um recurso natural que sofre intensamente com a má gestão dos recursos naturais os desequilíbrios ambientais em meio urbano são os córregos. Os córregos urbanos têm grande importância, pois podem abastecer a população de uma cidade inteira, atendendo boa parte de suas necessidades básicas. Porém, observa-se com frequência que esses mananciais são contaminados com esgotos domésticos e industriais, funcionando como depósitos de lixo, sofrendo com o escoamento de pesticidas e impermeabilização das áreas circunvizinhas (TUCCI, 2005). Essa realidade diminui intensa e drasticamente a qualidade e quantidade de água disponível para suprir as necessidades humanas (TUNDISI, 2003).

A Constituição Federal de 1989 dispõe que os mananciais urbanos servem para o abastecimento doméstico, recreação, irrigação de hortaliças e até mesmo para a criação natural e/ou intensiva de indivíduos destinados à alimentação humana. Dessa forma, toda cidade que utiliza essa fonte deveria ter um plano básico de controle e preservação de mananciais (BRASIL, 2005).

Um dos passos para elaboração de tais planos é o levantamento de informações. Esse levantamento pode-se incluir várias etapas e usufruir diversos instrumentos, incluindo a observação visual.

Nessa perspectiva, este trabalho teve como objetivo demonstrar a situação dos principais córregos urbanos na cidade de Cáceres-MT, buscando caracterizar de forma visual os seus aspectos físicos, além de descrever os desafios que esse tipo de ambiente encontra.

\section{METODOLOGIA}

Com cerca de 88.000 habitantes (IBGE, 2010), a cidade de Cáceres-MT, encontra-se no início do Pantanal Matogrossense e está situada às margens do rio Paraguai.

Em Cáceres, existem quatro córregos que nascem dentro dos limites do município, cortam a área urbana e deságuam no rio Paraguai, quais sejam: Sangradouro, Fontes, Canal do Renato e José Bastos, sendo estes, os córregos selecionados para a observação (Figura 01)

Mapeados os córregos, a próxima etapa do trabalho consistiu de visitas aos mananciais, durante o período de estiagem do ano de 2006 e 2012 (julho e agosto), com observação de todo o seu trajeto (nascente, médio curso e foz). Os itens observados durante as visitas foram: vegetação marginal, ocupação do entorno, presença de seres vivos, estado geral de preservação e odor. Os itens observados foram registrados em caderno de campo e demarcados os pontos com auxílio do GPS.

\section{RESULTADOS}

\section{I Córrego Sangradouro}

O córrego Sangradouro é o maior e o mais central da cidade; nasce na zona rural do município. Desde sua nascente suas margens são abertas (embora em vários pontos a vegetação tenha sido removida para construção de casas); a partir do bairro Cavalhada, o córrego passa a ser coberto por uma estrutura de concreto, até sua desembocadura no rio Paraguai próximo a Praça Barão do Rio Branco, um dos principais pontos turísticos da cidade.

A nascente (S16 $05^{\prime} 45.5^{\prime \prime}$ W57³9'10.8') deste córrego foi caracterizada como pouco degradada (com água transparente, presença de peixes e vegetação ciliar. Registros de pisoteio de gado foram evidenciados para este local. 


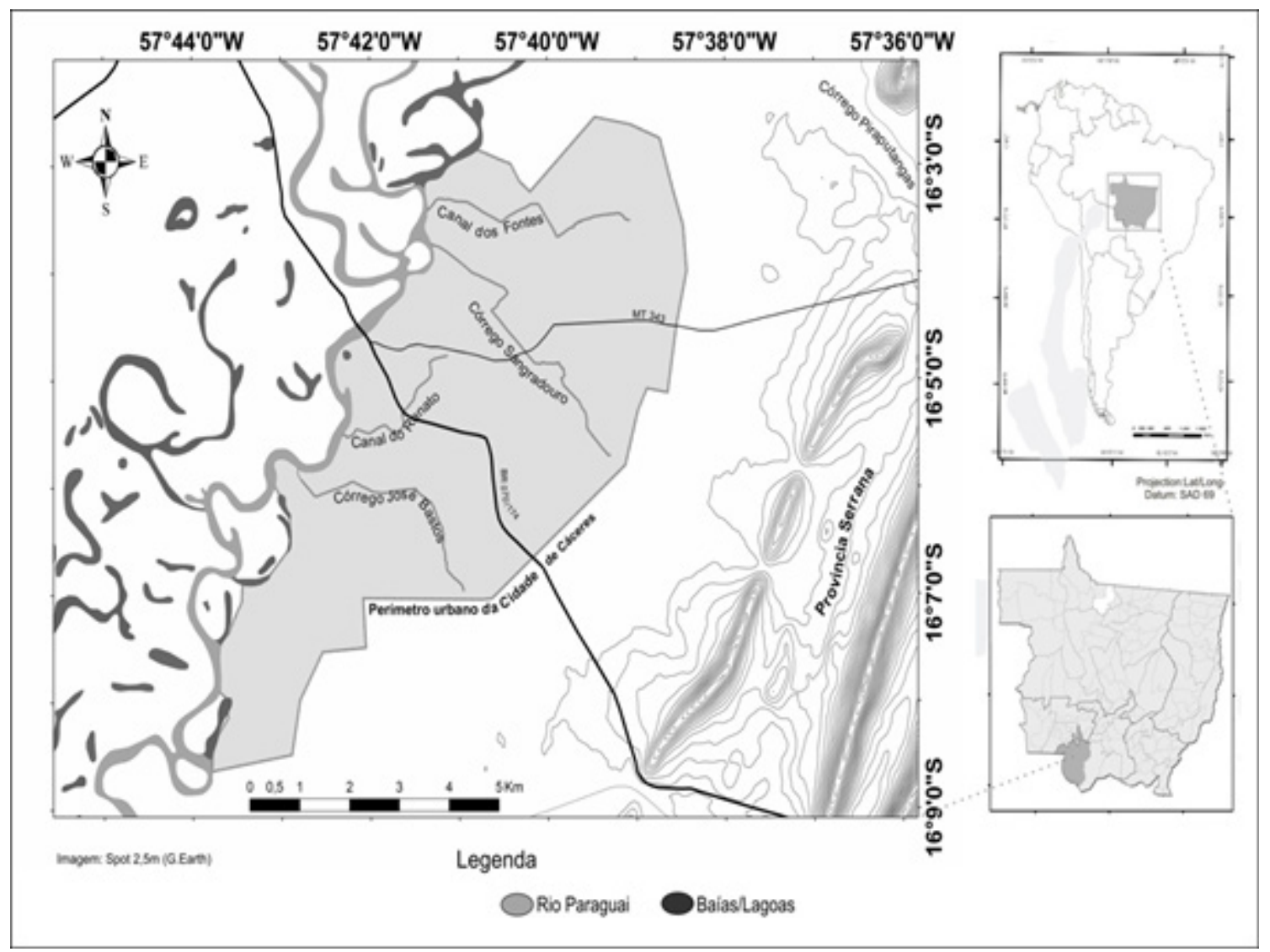

Figura 01. Córregos urbanos da cidade de Cáceres.

Em sua porção intermediária (S16 04 '25.0" W57 $\left.40^{\prime} 31.1^{\prime \prime}\right)$, o córrego apresentou características diferenciadas, como trechos em que o aspecto físico da água (transparente) permitia o lazer de banhistas, até aqueles com grande quantidade de vegetação aquática, sem a possibilidade de visualização da água. Foi observada que muitas casas que margeiam o córrego despejam o esgoto no manancial, explicando, desse modo, o mau cheiro ocorrente no local, bem como a grande quantidade de espuma e lixo nas águas.

A foz (S16 $03^{\prime} 42.0^{\prime \prime}$ W57 $\left.41^{\prime} 17.2^{\prime \prime}\right)$ do córrego apresenta-se totalmente canalizada. Em sua desembocadura, a água que chega ao rio Paraguai é verde escura, com mau cheiro e lixo.

O córrego Sangradouro tem as margens ocupadas em boa parte do seu percurso, com grande fluxo de pessoas durante o dia. Dentro do córrego foram encontrados resíduos de toda natureza: copos plásticos, garrafas PET, papelão, tampas de garrafas e sacolas plásticas. E possível que estes resíduos tenham sido depositados pela própria população (comerciantes e moradores do entorno ou pessoas que transitam ao longo do dia pelo local).

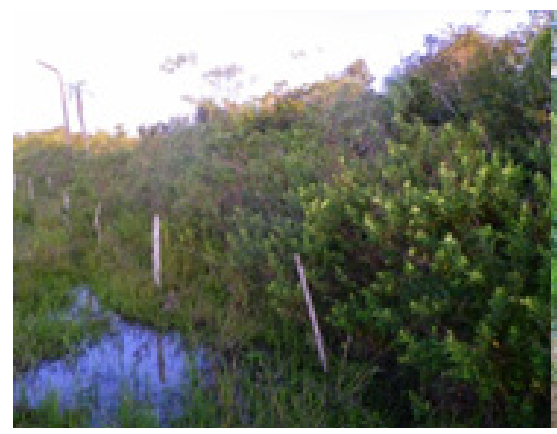

(A)

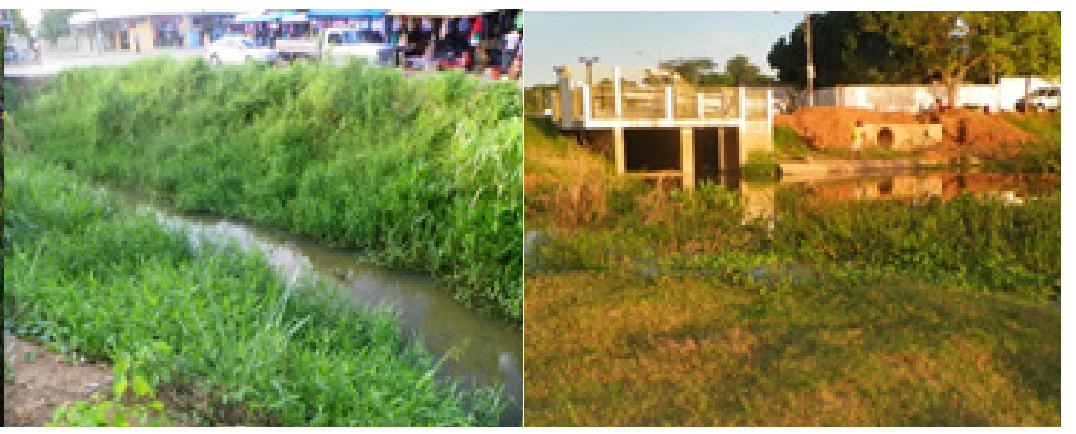

(B)
(C)

Figura 02. A) Nascente, B) Médio curso e C) Foz do córrego Sangradouro. 


\subsection{Córrego José Bastos}

O córrego José Bastos nasce na zona rural ao Sul da cidade de Cáceres-MT e corta bairros periféricos do município. Sua nascente (S16 07'01.7' W05740'43.9") é exuberante, sendo possível observar suas fontes e sua vegetação bem conservada. A poucos metros da nascente é identificada a presença de banhistas, com sensível aumento da quantidade de lixo ao redor.

No trecho intermediário $\left(\mathrm{S} 16^{\circ} 05^{\prime} 59.7^{\prime \prime}\right.$ W057²'39.2”) deste córrego, no Bairro Junco, a água tem aspecto turvo e o mau cheiro está presente. Há grande quantidade de macrófitas na água, indicando eutrofização. Lixo, peixes e pescadores se entremeiam em um ambiente insalubre (mau cheiro, água suja e espumosa) e muito degradado.

Em seu trecho final (S16 05'59.7" W05742'39.2"), já no Bairro Jardim das Oliveiras, o córrego é caracterizado pela presença de uma pequena quantidade de vegetação ciliar, a qual não recobre todo o trecho final, com água transparente e inodora, porém contendo lixo, sendo despejada no rio Paraguai em uma praia de areia.

O córrego José Bastos é caracterizado tanto pela perda de mata ciliar, quanto com as propriedades organolépticas alteradas (mau cheiro), sendo considerado como muito degradado em sua extensão mediana até a foz, com muitos vestígios de degradação, e considerado como conservado em sua nascente.

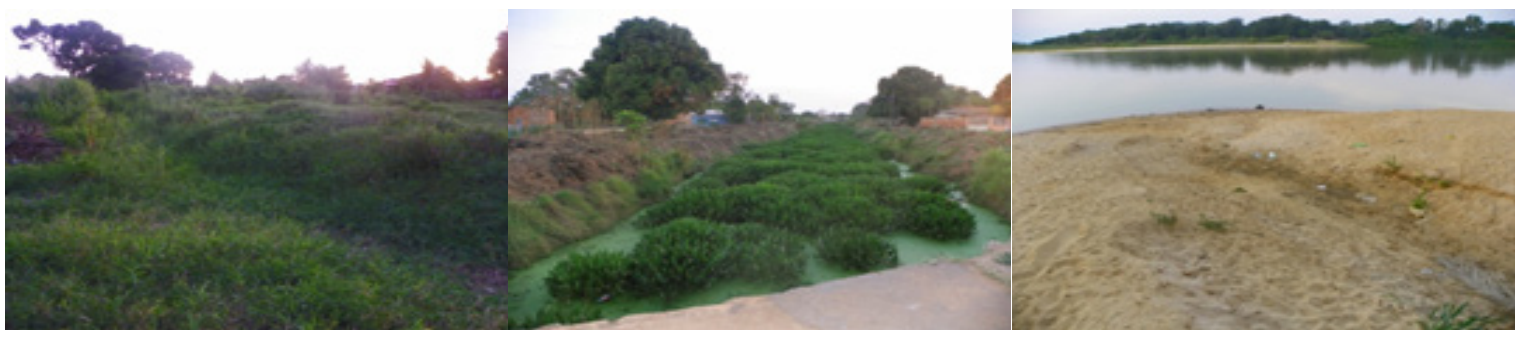

(A)

(B)

(C)

Figura 03. A) Nascente, B) Médio curso e C) Foz do córrego José Bastos.

\subsection{Canal do Renato}

O canal do Renato nasce no bairro Vila Mariana, área urbana da cidade. Sua nascente é cercada por casas, sem nenhuma proteção. Parte do córrego não é canalizada, seguindo seu curso; a outra parte é canalizada a céu aberto e concreto nas margens.

No local da nascente (S16 $04^{\prime} 44.9^{\prime \prime}$ W05741'05.7'), há grande quantidade de lixo e a água é coberta por plantas aquáticas, dificultando a visualização do seu leito. Nas margens, há poucos arbustos. Em alguns pontos as margens são rodeadas por capim e, embora esteja na área urbana, há indícios de pisoteio de gado.

O médio curso (S160.'58.3" W057 41'19.3") do córrego permeia os bairros Vila Mariana, Residencial Ana Paula e São Lourenço.
Três bairros cuja densidade demográfica é elevada. Suas margens estão totalmente degradadas, sem qualquer vegetação arbórea. Além disso, o córrego recebe esgoto de encanamentos ativos, tornando a água tem cor azul-esverdeada com vegetação aquática e gordura na superfície.

Sua desembocadura (S16 $05^{\prime} 26.2$ " W05742'07.3") está localizada ao lado do Frigorífico municipal e todo seu esgoto é lançado no córrego. Apesar de receber tratamento antes de ser lançado na água, o efluente do frigorífico apresenta mau cheiro. $\mathrm{O}$ rio Paraguai recebe as águas do Canal do Renato sob um aspecto verde escuro, com presença de espuma e gorduras. A foz do Canal do Renato é um local de travessia de pedestres e animais; na cheia, a água fica represada, dando ao ambiente um aspecto insalubre.

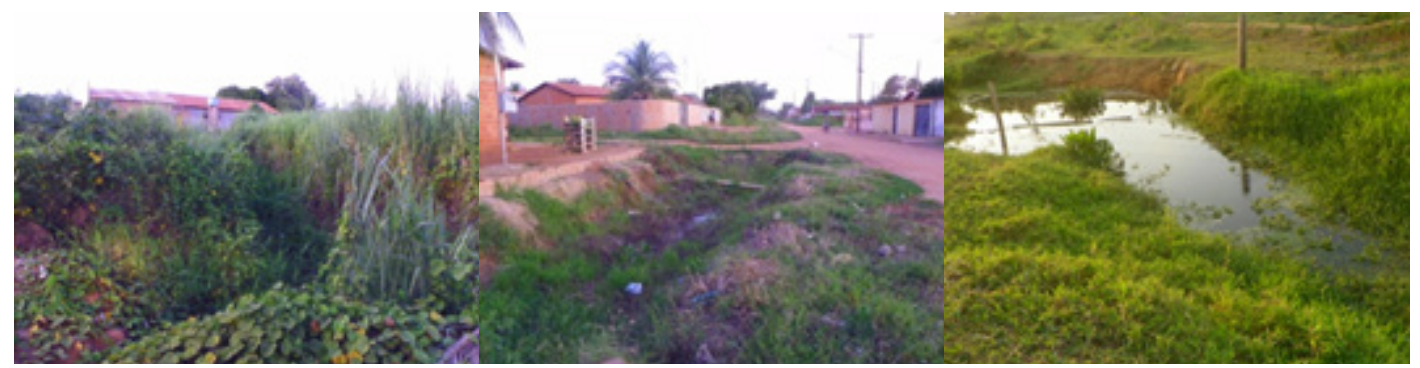

(A)

(B)

(C)

Figura 04. A) Nascente, B) Médio curso e C) Foz do córrego do Renato. 


\subsection{Canal dos Fontes}

O Canal dos Fontes (S16 03'38.7" W057³9'52.1") localiza-se ao norte do centro da cidade. Não foi possível encontrar a sua nascente, pois seu trajeto não é bem definido em época de seca, em que mesmo com auxílio de GPS encontramos vestígios de águas em canais, porém sem indícios característicos de nascentes. Dessa forma, o córrego foi observado desde o bairro Joaquim Murtinho até a área arbórea onde está a sua foz na Baía do Malheiros, ligada ao rio Paraguai.

Este córrego apresentou água barrenta e com odor forte. Não há muitas casas ao seu redor, porém a vegetação ciliar foi removida mesmo assim. Foi registrada grande quantidade de plan- tas aquáticas em seu leito. Peixes também foram observados, apesar do córrego sofrer com a grande quantidade de veículos ao seu redor, e pisoteio de gado. O lixo foi encontrado em todo o trajeto. Ao contrário do que foi observado no médio curso, a desembocadura (S16 ${ }^{\circ} 03^{\prime} 08.5^{\prime \prime}$ W05741'12.5") do Canal dos Fontes é repleta de vegetação ciliar, com mata preservada, e a água possui aspecto límpido. Foi constatada a presença de animais silvestres, como cutia e capivara, além de pássaros, nas margens e vegetação ao redor. Há poucos vestígios antrópicos. O córrego dos Fontes deságua no rio Paraguai com aspecto natural e sem características peculiares de degradação.

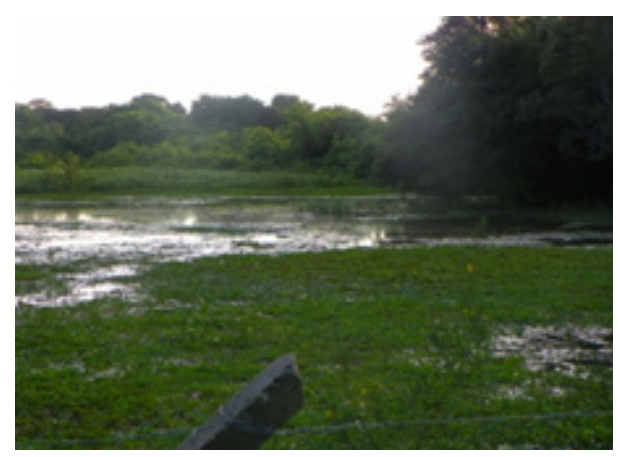

Figura 05. A) Médio curso do córrego dos Fontes. B) Foz do córrego dos Fontes

\section{DISCUSSÃO}

A má ocupação do solo associada ao desmatamento, canalização e deposição inadequada de resíduos, pode ocasionar problemas que abrangem toda a população de uma cidade. O processo de urbanização traz profundas modificações no uso do solo, que por sua vez causa marcas permanentes nas respostas hidrológicas das áreas urbanizadas (TUCCI, 2005).

A legislação de proteção ambiental aprovada na maioria dos Estados brasileiros protege os mananciais e os corpos d'água. Nessas áreas é proibida a ocupação urbana e outros usos que possam comprometer a qualidade da água e gerar impactos físicos. Ainda assim, em muitos locais as agressões aos cursos d'água são registradas com frequência. Rebouças (2006) argumenta que as catástrofes que afetam especialmente as comunidades urbanas, como as enchentes, são devidas a causas antrópicas, tais como impermeabilização dos solos e propostas equivocadas no manejo dos recursos hídricos.

Para Tucci, (2005), as enchentes nas cidades são processos gerados principalmente pela falta de disciplinamento da ocupação urbana. Muitas áreas protegidas por lei são ocupadas de forma desordenada, são construídas casas e asfaltos de forma a impermeabilizar o solo, que na época das cheias não absorve as águas das chuvas, acelerando o escoamento superficial que por sua vez ocasiona às enchentes que geram grandes prejuízos e desconfortos às pessoas que residem nestes locais. Não é possível afirmar com precisão as causas das enchentes ocorridas em Cáceres, mas é muito provável que a má conservação dos córregos, bem como a canalização dos córregos, esteja contribuindo para a ocorrência destes eventos, tendo em vista o córrego Sangradouro ter transbordado logo após ter sido canalizado.

Segundo Pompêo (2000), a impermeabilização do solo provoca maior vazão da água, tendo esta que ser escoada para lagos, reservatórios e rios. Caso não haja escoamento adequado pode-se ocorrer enchentes e inundações devido a retirada de vegetação ciliar e a dificuldade de infiltração da água no solo - impermeabilização.

A eutrofização de um manancial está rela- 
cionada com a grande quantidade de matéria orgânica despejada em seu interior (Tundisi, 2003). De acordo com Hutchinson (1957), a eutrofização provoca uma elevada produtividade primária, devido ao alto nível de concentração de nutrientes, provenientes principalmente de efluentes domésticos, industriais e agrícolas. Tucci, (2005) relata que esta produtividade pode ocasionar um aumento excessivo no aumento da biomassa, tornando o ambiente mais raso e perdendo suas características naturais, além do que aumentam a quantidade de algas gerando toxicidade.

Neste estudo, foi possível perceber muitos encanamentos de esgoto desembocando em todos os córregos, bem como evidentes sinais de eutrofização. Esses encanamentos observados foram também relacionados como ativos, pois pôde ser constatada água sendo depositada nos córregos, sendo que esta continha coloração turva e odor característico de efluentes domésticos. Porém não podemos considerar o manancial como tóxico, haja vista a presença de peixes em todos.

A mata ciliar é uma vegetação que margeia os córregos, sendo, portanto importantíssima para a manutenção da qualidade dos mananciais, tendo em vista que suas raízes seguram o solo evitando a erosão (MARTINS, 2007). Caso ocorra erosão do solo para dentro do manancial, este fica prejudicado, em função da redução da profundidade, afetando a qualidade da água e o ecossistema como um todo (KRUPEK \& FELSKI, 2006).

As matas ciliares são alvos de degradação constate devido ao fato de não haver planejamento em áreas urbanas; as casas são comumente construídas margeando os corpos hídricos (ARAÚJO et al., 2004). Essa foi uma situação muito presente nos córregos observados no presente estudo em que a mata ciliar foi totalmente suprimida, contendo gramíneas como mantenedoras do solo, com risco iminente de agravamento de erosão.

O odor é um importante aspecto a se considerar quando se trata de qualidade da água, tendo em vista que muitas substâncias, que quando presentes em grandes quantidades são nocivas ao ser humano, podem estar presentes na água, tais como: ferro, manganês, matéria orgânica, cálcio, cloretos, cloro, materiais em suspensão, etc. Além disso, uma água que apresente cor, turvação, cheiro ou sabor, não poderá ser considerada de boa qualidade, devendo ser sujeita a tratamento específico (AQUAAMBIENTE, 2004).

As espumas nos corpos d'água, incluindo os que foram observados neste estudo, podem estar relacionadas ao alto teor de surfactantes (detergentes) provenientes dos esgotos domésticos e lançados sem tratamento nos canais. Liliamtis e Mancuso (2003) observaram situações semelhantes em Pirapora do Bom Jesus - SP, cidade que sofre com a poluição do rio Tietê. Esse odor presente nos córregos analisados foi agravado conforme foram constatados encanamentos em seus cursos. Quanto mais encanamentos havia, e todos ativos, mais forte era o cheiro característico de efluente doméstico.

Os resíduos sólidos são desafios para todos os municípios do planeta. A coleta e deposição são ações que devem ser eficazes para a boa manutenção do equilíbrio ambiental. Entretanto, muitas pessoas, bem como o poder público, não se sensibilizam com o aspecto insalubre provocado, sendo os córregos urbanos escoadouros do lixo produzido pelas populações.

Devido a canalização de alguns córregos, esses resíduos podem ficar presos no canal, impedindo a passagem da água, ocasionando as enchentes e inundações. Essa situação foi observada também, pelo projeto Iguaçu, cujo tema é o lixo e as enchentes no estado do Rio de Janeiro. Os levantamentos realizados através desse projeto permitiram concluir que o lixo é um dos grandes vilões das enchentes ocorrentes na região da baixada fluminense, e é também um fato encontrado nos quatro córregos urbanos da cidade de Cáceres.

\section{CONCLUSÃO}

Foi possível identificar que os córregos Sangradouro e Canal do Renato são os mais degradados e poluídos. Na nascente do córrego Sangradouro, a poluição não é visível; essa realidade permanece até o córrego entrar na área urbana, quando a degradação torna-se bastante aparente. No Canal do Renato, a situação é diferente, pois a nascente está localizada em área urbana, tornando-a um ambiente muito fragilizado.

Aparentemente, o canal do Renato apresenta maior poluição, se comparado ao córrego Sangradouro, pois foi possível observar gordura, espuma, lodo e odor em quase todo o seu trecho.

Os córregos José Bastos e Canal dos Fontes estão nivelados no que concerne à degradação e poluição; entretanto, se comparados com os outros dois córregos, estes encontram-se em melhores condições de preservação.

Toda sociedade deveria preocupar-se com questões relacionadas aos córregos urbanos, buscando um olhar mais sensível e uma perspectiva do futuro, pois, considerando os resultados deste levantamento, percebe-se que não se trata apenas 
de um problema ambiental, há vertentes sociais envolvidas (ocupação desordenada), aumentando as preocupações para com as condições de vida da população, não só em relação ao comprometimento dos recursos hídricos.

Há vários desafios para o poder público e para a sociedade, entre os quais se destacam: implantação de um sistema de tratamento de efluente, deposição adequada de resíduos sólidos e uso ordenado do solo. É necessário que todos se envolvam e refaçam a história dos córregos urbanos em Cáceres.

Desta forma, este trabalho contribui e se propõe a instigar a implementação de planos de manejo que contemplem a recuperação dessas áreas que são importantes como canais de drenagem, além de proporcionarem beleza cênica e melhor qualidade ambiental e de vida, quando conservados.

\section{REFERENCIAS}

BRASIL. Conselho Nacional de Meio Ambiente. Resolução CONAMA n ${ }^{\circ}$ 357. Dispõe sobre a classificação dos corpos de água e diretrizes para o seu enquadramento, bem com estabelece as condições e padrões de lançamento de efluentes, e dá outras providêmcias. Brasília: 2005. Diário Oficial da União, 17 de março 2005.

BRASIL. IBGE. Instituto Brasileiro de Geografia e Estatística. 2010 www.ibge.gov.br/catálogos/ indicadores. Acesso em março 2012.

Rio de Janeiro. Projeto Iguaçú, Projeto de Controle de Inundações e Recuperação Ambiental das Bacias dos Rios Iguaçu, Botas e Sarapuí: O Lixo e as Enchentes, o que você tem a ver com isso? Cartilha técnica. 2009.

ARAUJO, M. M.; LONGHI, S. J.; BARROS, P. L. C.; BRNA, D. A.: Caracterização Da chuva de sementes, banco de sementes do solo e banco de plântulas em Floresta Estacional Decidual Ripária Cachoeira do Sul, RS, Brasil. Scientia Florestalis. N.66, P.128-141, Dez.2004

BENETTI, A. \& BIDONE, F. O meio ambiente e os recursos hídricos. In: TUCCI, C.E.M. (Org). Hidrologia, ciência e aplicação. $3^{\circ}$ ed. Porto Alegre: Editora da UFRGS/ABRH, 2004. p.849-875.

HUTCHINSON, G.E. 1957 A Treatise on Limnology: Geography Physics and Chemistry. v.1, New York: John Wiley \& Sons. 1.015p.
KRUPEK, R A.; FELSKI, G.: Avaliação da Cobertura Ripária de Rios e Riachos da Bacia Hidrográfica do Rio das Pedras, Região Centro-Sul do Estado do Paraná. Revista Ciências Exatas e Naturais, Vol. 8 n 2, Jul/Dez 2006

LEOPOLD, L.B., 1968. Hydrology for Urban Planning - A Guide Book on the Hydrologic Effects on Urban Land Use. USGS circ. 554, 18p.

LILIAMTIS, T. B.; MANCUSO, P. C. S. A geração de maus cheiros na rede coletora de esgotos do município de Pereira Barreto: um problema de saúde publica. Revista Saúde e Sociedade. v.12, n 2 , 2003.

MARTINS, S. V.: Recuperação de matas ciliares. $2^{\mathrm{a}}$ Ed. Revista e ampliada. Viçosa: Editora Aprenda Fácil, 2007. 255p.

PIRES, J. S. R. \& SANTOS, J. E. Bacias Hidrográficas - Integração entre meio ambiente e desenvolvimento. CIÊNCIA HOJE, Rio de Janeiro, v. 19, n. 110, p. 40- 45, 1995.

POMPÊO, C. A. Drenagem Urbana Sustentável. Revista Brasileira de Recursos Hídricos, n.1, p. 15-23, Jan/Mar, 2000.

REBOUÇAS, Aldo da C. Água doce no mundo e no Brasil. In: REBOUÇAS, Aldo da C.; BRAGA, Benedito; TUNDISI, José Galizia. Águas doces no Brasil: capital ecológico, uso e conservação. 3. ed. São Paulo: Escritura Editora, 2006.

SUNDFELD, Carlos Ari. O Estatuto da cidade e suas diretrizes gerais. In: Estatuto da cidade (comentários à Lei Federal 10.257/2.001). Coordenadores: Adilson Abreu DALLARI e Sérgio FERRAZ. São Paulo: Malheiros, 2.003, p. 54

TUCCI, C. E. M.; HESPANHOL, I. e CORDEIRO NETTO, O. M. (2003). Cenários da gestão da água no Brasil: uma contribuição para a "visão mundial da água". Salvador. Disponível em: <http://www. profrios.hpg.ig.com.br/html/artigos/cenarios.html>. Acesso em: 26/03/2012.

TUCCI, C.E.M. Gestão de Águas Pluviais Urbanas/ Carlos E. M.Tucci - Ministério das Cidades - Global Water Partnership - Wolrd Bank - Unesco 2005.

TUNDISI, J. G. Água no século XXI: enfrentando a escassez. São Carlos: Rima, 2003. 